IZA DP No. 6066

Work and Wage Dynamics around Childbirth

Mette Ejrnæs

Astrid Kunze

October 2011

Forschungsinstitut zur Zukunft der Arbeit Institute for the Study of Labor 


\title{
Work and Wage Dynamics around Childbirth
}

\author{
Mette Ejrnæs \\ University of Copenhagen \\ and SFI \\ Astrid Kunze \\ $\mathrm{NHH}$ - Norwegian School of Economics \\ and IZA
}

Discussion Paper No. 6066

October 2011

\author{
IZA \\ P.O. Box 7240 \\ 53072 Bonn \\ Germany \\ Phone: +49-228-3894-0 \\ Fax: +49-228-3894-180 \\ E-mail: iza@iza.org
}

Any opinions expressed here are those of the author(s) and not those of IZA. Research published in this series may include views on policy, but the institute itself takes no institutional policy positions.

The Institute for the Study of Labor (IZA) in Bonn is a local and virtual international research center and a place of communication between science, politics and business. IZA is an independent nonprofit organization supported by Deutsche Post Foundation. The center is associated with the University of Bonn and offers a stimulating research environment through its international network, workshops and conferences, data service, project support, research visits and doctoral program. IZA engages in (i) original and internationally competitive research in all fields of labor economics, (ii) development of policy concepts, and (iii) dissemination of research results and concepts to the interested public.

IZA Discussion Papers often represent preliminary work and are circulated to encourage discussion. Citation of such a paper should account for its provisional character. A revised version may be available directly from the author. 
IZA Discussion Paper No. 6066

October 2011

\section{ABSTRACT \\ Work and Wage Dynamics around Childbirth ${ }^{*}$}

This study investigates how the first childbirth affects the wage processes of highly attached women. We estimate a flexible fixed effects wage regression model extended with post-birth fixed effects by the control function approach. Register data on West Germany are used and we exploit the expansionary family policy during the late 1980 s and 1990 s for identification. On the return to work after the birth, mothers' wages drop by 3 to 5.7 per cent per year of leave. We find negative selection back to full-time work after birth. We discuss policy implications regarding statistical discrimination and results on family gap.

JEL Classification: $\quad$ C23, J18, J22, J24, J31

Keywords: wages, parental leave, human capital, return to work, non-random selection

Corresponding author:

Astrid Kunze

$\mathrm{NHH}$ - Norwegian School of Economics

Helleveien 30

$\mathrm{N}-5045$ Bergen

Norway

E-mail: astrid.kunze@nhh.no

\footnotetext{
${ }^{*}$ The authors gratefully acknowledge the helpful comments of M. Browning, B. Honoré, K.G. Salvanes, B. Weinberg, U. Schönberg, C. Bollinger, $\varnothing$. Nilsen, and B. Tungodden along with seminar participants at the University of Mannheim and the Centre for European Economic Research (ZEW), the University of Ohio, the University of Kentucky and the University of Oxford.
} 


\section{Introduction}

An important matter in both political and economic debate is how to integrate and retain women in the labour market. One particularly important concern is how women with children perform in the labour market, with an indicator of their relatively poorer performance being the so-called "family gap", the relatively lower hourly wages of women with children compared to women without children. ${ }^{1}$ To achieve a better family-work balance, parental leave policy has been widely employed. The main aspect of these schemes is the right to return to a previous position of employment within a certain period (job-protected maternity leave).

Work interruptions related to birth are expected to affect mothers' wages directly through changes in the formation of human capital. Identifying the causal effect is challenging, as women who return to work following childbirth may differ from those who do not. Therefore, comparing the wages of women before and after childbirth may yield biased estimates. International statistics show that the employment rates of women with young children are persistently lower when compared to overall female employment. ${ }^{2}$ Hence, the group who returns to work after birth is potentially a non-randomly selected group and it is then interesting to consider which women from the skill distribution return to work.

In this study, we investigate how the first childbirth affects the wage processes of women with a focus on the return to human capital before and after birth and the effects of the duration of parental leave. The novelty in our work is that the wage model explicitly accounts for the non-randomness of the return to work decision following birth. More particularly, the standard

\footnotetext{
${ }^{1}$ For an overview of the family gap, see, e.g. Waldfogel (1998b).

${ }^{2}$ Employment rates for mothers with children younger than 6 years of age in 1999 were $61.5 \%$ in the US, $55.8 \%$ in the UK, $51.1 \%$ in Germany and $56.2 \%$ in France. They were higher in Scandinavian countries, but lower in Southern European countries. See OECD (2001).
} 
wage regression model with unobserved heterogeneity is extended with post-birth fixed effects. This is meant to capture changes in motivation, energy and commitment in connection with birth. The effects after childbirth in the wage regression are identified through a number of expansions of nationwide maternity leave durations over a relatively short period.

The empirical analysis is based on a large sample of women who were highly attached to the labour market. Data are extracted from the Institute for Employment Research (IAB) employment register covering the period 1975-2001. The sample is constructed such that the mothers' employment and wage histories are observed from the beginning of their working careers and include interruptions of work relating to first birth (parental leave). The large sample of 30,000 women allows us to estimate the wage processes separately for education groups and women who become mothers at some point in our observation period (the mother sample) and women who remain childless (the non-mother sample). Hence, heterogeneity of behaviour among women across the education distribution can be investigated. An additional advantage of the data is that they cover an interesting period of family policy expansion in Germany. During a relatively short period of time, parental leave was expanded from 6 months, in the period 1979 to 1986 , to 3 years in $1992 .^{3}$ The large variation over time makes Germany's parental leave policy very suitable for our analysis.

While some studies have moved in the direction of controlling for the complete work history and sequence of events (e.g. Datta Gupta and Smith 2002; Nielsen et al. 2004), and allowing for heterogeneity in the parameters across education groups (e.g. Anderson et al. 2002; Datta Gupta and Smith 2002), no study has explicitly modelled the post-birth fixed effects. This

\footnotetext{
${ }^{3}$ See Ondrich et al. (1996), Dustmann and Schönberg (2008), and Schönberg and Ludsteck (2007) for evidence of the effects of these reforms. However, none of these studies considers the return to work after birth and relative changes over time, or indirect effects on the wage processes.
} 
study shows new evidence that mothers who return to full-time work are negatively selected, and this holds across all education groups. This implies that standard estimates comparing the wages among women before and after return (e.g. first differences) overstate the causal effect of interruption on a woman's wages. While there has been some evidence on return behaviour (e.g. Lalive and Zweimüller 2009; Burgess et al., 2008), little is known about the randomness of this decision.

Institutions regarding the length of parental leave and also childcare coverage vary greatly across the OECD countries and the effect of the extension of parental leave is likely to depend on the specific institutions. ${ }^{4}$ Therefore, our results may be informative on behavior around childbirth in countries with similar institutions; e.g. the Netherlands, Spain and Portugal that are all countries characterized by relatively long durations of job protected parental leave and low provision of childcare for 0 to 2 years old. At the same time Germany is one of the countries with the largest family gap (Harkness and Waldfogel 2003; Davies and Pierre 2005) which casts doubts on how and whether generous parental leave policies have affected the labour supply. In fact, previous evidence for full-time workers in West Germany suggests that an important source of the family gap is the large drop in wages of around 10-20 per cent per year on the return to work following birth (Kunze 2002; Ondrich et al. 2003; Ejrnæs and Kunze 2004; Schönberg and Ludsteck 2007; Beblo et al. 2009).

The main result in this study is that on the return to full-time work after the first birth, mothers' wages drop by 3 to 5.7 per cent per year of leave, and these estimates are smaller than those from first differences. When we estimate our model in first differences by the control function approach, the estimates are lower because we find negative selection back to work

\footnotetext{
${ }^{4}$ One may expect effects to vary depending on whether leave periods are short or long (see Ruhm, 1998), and childcare coverage is high or low.
} 
after birth. This effect becomes empirically important because the return rate of mothers is only about 50 per cent. This means that those mothers who actually return are those who are exposed to the greatest loss. This is plausible if, for example, highly productive women also have highly productive partners and hence the marginal utility of income is relatively lower. We also find that the return rates decline for highly attached women across our observation period and therefore the effect of negative selection is aggravated over time. Therefore, this finding indicates that the mother's position in the labour market has not improved. It is also noteworthy that our results relate to the effects throughout the total duration of leave after first birth, rather than the cost per child related to leave. Finally, a comparison of the predicted wage processes for mothers and women who remain childless shows sources of family gap around birth.

The remainder of the paper is organized as follows. Section 2 provides the institutional setting for Germany. Section 3 presents the econometric model, while Section 4 describes the data and summary statistics. Section 5 presents the results. Section 6 discusses the policy implications and Section 7 concludes.

\section{German parental leave legislation (1981 to 1996)}

Women who gave birth from 1981 until the end of 1985 were eligible for 6 months of jobprotected maternity leave in Germany. These maternity leave provisions were regulated in the Mutterschutzgesetz introduced in 1968. A main component of maternity leave is that it guarantees the right to return to the previous position with the previous employer (job-protected maternity leave). The law gives working women the right to 6 weeks leave before expected birth and 8 weeks after birth; meaning that working during the 8 weeks after birth is prohibited. The 
14 weeks of leave are fully paid. Women obtain compensation for income loss equivalent to the average wage for the 3 months before the start of the protected leave period. Compensation is shared by health insurance, the federal government and the employer. Since 1979, women have had access to an additional 4 months of job-protected leave, however, this is unpaid in the sense that the only benefits are paid for by the federal government and health insurance. From 1979 until 1985, benefit payments from the third month after birth were fixed at a nominal level of 750 German marks (about 383 Euros). That is, about 20 to 30 per cent of average entry wages as observed in the IABS. These have been subsequently reduced and eligibility rules have been introduced along with a number of other changes.

Since 1985, maternity leave has been reformed several times. The 1986 reform was a major reform as it introduced longer parental leave but also extended rights to benefit payments to non-working mothers, and extended the right to parental leave to fathers. ${ }^{5}$ The main benefit of the parental leave reforms that this study exploits is the sequential extension of the periods during which the right to return to the previous job can be used (job-protected leave). By 1992, the job-protection period had been increased to 3 years after birth. For a full overview, see Table 1. In the following, we refer to the complete period of job-protected leave as (job-protected) parental leave.

[Table 1 about here]

In West Germany, traditionally, childcare is mostly organized by public providers, is only part time (that is 3-4 hours a day), and is primarily for children aged 3-6 years and this has

\footnotetext{
${ }^{5}$ Mothers and fathers can now share parental leave from the third month after birth. We do not include this change, as it is rare for fathers to take parental leave: less than 3 per cent of fathers in Germany in 1995 took parental leave.
} 
not changed very much during our period of interest. In 2001, on average less than 10 percent of all children 0-2 years old were in childcare. West Germany is in terms of long durations of parental leave and low childcare coverage most similar to countries such as the Netherlands, Spain and Portugal (OECD Employment Outlook, 2001).

It is an empirical question whether the expansion of the duration of protected leave directly affects the decision to return to work after birth, and whether the effect is positive or negative. In an international study, Ruhm (1998) concluded that short leave durations have a positive impact on employment while longer periods of leave have a negative effect. Lalive and Zweimüller (2009) found a decline in return rates in Austria when paid parental leave was expanded from 1 to 2 years. Other studies showed spikes around the time of expiry of paid and unpaid leave; see Burgess et al.(2008) for Britain and in Schoenberg and Ludsteck (2007) for Germany.

\section{The econometric framework}

Our model to estimate wage processes around birth builds on a wage regression with unobserved heterogeneity, as this is quite standard in the literature, and we extend it with post-birth fixed

effects. The standard part of the model includes, along with a vector of observed human capital characteristics, $X_{i t}$, the duration of leave related to first birth, $m_{i t}$, an unobserved individual-specific effect component $\mu_{i}$, and a time-varying and individual-varying shock, $\epsilon_{i t}$. The individual-specific effect, $\mu_{i}$, captures the general unobserved ability or preference for work. 
The model allows for varying coefficients before and after birth and in levels is written as: ${ }^{6}$

$$
\begin{aligned}
\ln w_{i t} & =1\left(t<t_{i}^{\text {birth }}\right) X_{i t} \beta^{\text {before }} \\
& +1\left(t \geq t_{i}^{\text {birth }}\right) X_{i t} \beta^{\text {after }}+1\left(t \geq t_{i}^{b i r t h}\right) \delta m_{i t}+1\left(t \geq t_{i}^{\text {birth }}\right) \gamma_{i} \\
& +\mu_{i}+\varepsilon_{i t}
\end{aligned}
$$

where $1(\cdot)$ is an indicator function equal to one if the expression in parentheses holds and zero otherwise. $t^{\text {birth }}$ denotes the period of first birth. For illustration, the model is written here in terms of the key parameters, $\beta$ (before and after first birth) and $\delta$, the effect through leave related to birth. A well-noted challenge when estimating this model is unobserved heterogeneity, $\mu$, and its correlation with $m_{i t}$ (e.g. Waldfogel 1998a). This will be taken into account by estimation of equation (1) in first differences. ${ }^{7}$

With extension of the standard model, the unobserved individual effect can change after birth; this is modelled by the post-birth individual-specific effect $\gamma_{i}{ }^{8}$ This is meant to capture the fact that the change in motivation, energy and commitment in connection with birth may be heterogeneous across mothers. Thus, the impact of birth on women's wage processes works through three channels: the change in the return to human capital $\left(\beta^{\prime} s\right)$, the effect through the duration of parental leave $(\delta)$ that may be caused by the depreciation of human capital, and

\footnotetext{
${ }^{6}$ In the estimation, we ensure that the wage process is a continuous function of accumulated experience.

${ }^{7}$ Note, the estimated specification also controls for mobility (plant, occupation and sector) and time effects. Another minor extension that we introduce is that wages can increase at a declining rate, even before birth. In a wage regression conditional on being a mother, this can capture effects through the timing of birth. Hence, it may be that women with a relatively lower career progression decide to have a child.

${ }^{8}$ Note that $\mu$ captures unobserved heterogeneity across individuals before and after birth. Hence, $\gamma$ is essentially zero or equal to a constant before birth. It is only after birth that $\gamma$ becomes crucial. The standard assumptions on individual effects still apply: both $\mu$ and $\gamma$ may be correlated with $X$ and $m$, and $E(\mu)=$ $E(\gamma)=0$. Empirical estimation shows that relaxing these assumptions leaves the results unchanged.
} 
the change in the individual-specific effect related to birth $\left(\gamma_{i}\right)$.

By explicitly modelling $\gamma_{i}$ we highlight two potential problems in estimating equation (1). First, estimation by first differences does not remove $\gamma_{i}$ and a potential source of endogeneity remains. ${ }^{9}$ Second, as not all women return to work after childbirth, we only observe wages after birth for a selected group (a non-random sample). The selection problem arises because $E\left(\gamma_{i} \mid s_{i}^{t}=1\right) \neq 0$, where $s_{i}^{t}$ is an indicator for whether the woman returns after childbirth and $t$ indexes the period after birth when the woman returns. To deal with these problems, we estimate the wage model in equation (1) in first differences and replace $\gamma_{i}$ with a control function.

The control function is based on the following selection equation describing the return to work after childbirth:

$$
s_{i}^{t}=\mathbf{1}\left(Z_{i(t)} \rho+X_{i(t)} \tau+v_{i}>0\right), \quad t=\text { return }
$$

where $Z_{i(t)}$ is a set of variables and $v_{i}$ is an error term assumed to be normal. In the empirical analysis, we focus on the period before and after first birth, and therefore only one return decision for each woman is observed and $X_{i(t)}$ and $Z_{i(t)}$ are measured before first birth. We cannot estimate $\gamma_{i}$, but only recover the covariance between $\gamma_{i}$ and $v_{i}$. This is sufficient to consistently estimate the key parameters. The identifying assumption is that if we condition on $v$, then $s$ and $Z$ are exogenous to the wage process. Our approach is closely related to Heckman's sample selection model, since the inverse Mills ratio is used as the control function (see e.g. Blundell and Dias (2009)).

In this model, the endogeneity of the fertility decision is not considered explicitly. Note, however, that we estimate the wage processes conditional on the individual work history and

\footnotetext{
${ }^{9}$ In the first-difference model, $\gamma_{i}$ will not be swept out in the first wage spell after birth.
} 
fixed effects. So what we assume is that the fertility decision conditioned on these characteristics is exogenous. We acknowledge that this approach does not completely remove the problem, yet it is very difficult to find valid instruments for fertility. To allow for more heterogeneity in the wage processes, we estimate the wage model separately for mothers and non-mothers and by education group.

To identify the post-birth parameters, we use the policy changes of parental leave as the set of exclusive restrictions. Women who become mothers during the period 1981 and 1985 are eligible for 7.5 months of leave (the reference group). Women with births after 1985 are subject to the expansions in parental leave and this generates the variation used to estimate the effect of the expansion on the return after birth (see Table (1)). We assume that the policies did not affect the wage process either directly or through the selection into motherhood or the timing of birth. The particular question for our application is whether the policy changes have induced changes in the timing of first birth, as we are only interested in the effect through leave after the first birth. Lalive and Zweimüller (2009) have shown that the expansion of paid leave in Austria significantly increased the likelihood of second births. It is not obvious though that this effect extends to the timing of first births in the German context of unpaid leave and extremely low fertility. A caveat of our data is that we do not observe the exact number of children and the birth of the second child. Therefore, we cannot estimate the cost per child through leave and we focus on the total effect of leave related to first birth. 


\section{Data}

We extract a sample of highly attached mothers from the 2 per cent IAB employment sample $(\mathrm{IABS})^{10}$ which contains the population of workers in Germany with at least one employment spell covered by social security. This data source represents about 80 per cent of the total employment population in Germany. ${ }^{11}$ These register data are of very high quality, because of both their high accuracy of wages (which are based on taxable income) and accurate employment history data. ${ }^{12}$ We apply the usual adjustments to the data. For detailed descriptions of the data source, see Bender et al. (2000).

\subsection{Data sample and variables}

We select cohorts of highly attached West German mothers who entered the labour market between 1975-1994 and whose post-schooling work history is observed from the start. The last period they can be observed is 2001 . We define highly attached mothers as those who have never worked part-time before birth and who have worked for at least 1 year full-time until birth. ${ }^{13}$ We keep women who were on job-protected leave during the period 1981-1995 and not later, to ensure that we can follow them sufficiently long after birth (5 years). This also implies that everybody was at least eligible for 7.5 months of parental leave (including maternity leave of 14 weeks). Only for returners are wages observed after birth. We focus on wage outcomes for those

\footnotetext{
${ }^{10}$ IABS is an abbreviation for the Institut für Arbeitsmarkt und Berufsforschung Sample.

${ }^{11}$ Not included are civil servants, the self-employed, students, unpaid family workers and people who are not eligible for benefits from the social security system.

${ }^{12}$ For more details on the IABS see Appendix 7.1.

${ }^{13}$ By construction, we exclude from our sample those who do not start work in a job covered by the social security system after education, and are never in full-time work. Furthermore, we exclude those who start working after education and drop out to non-work or part-time work years before having a child.
} 
returning to full-time work within 3.5 years. We chose this duration as the cut-off point so as to have enough returners within every year and education group. ${ }^{14}$ Non-returners are those not staying highly attached and include switchers to part-time work or those dropping out of work. We use only those periods until the second interruption reported in the data. This is to focus on the effects around first births through first parental leave. ${ }^{15}$ For the counterfactual analysis, we keep women for whom we do not observe an interruption during their labour career and who are still childless by age 39 years (the non-mothers sample). ${ }^{16}$ Finally, we distinguish between three education groups: low skilled (10 years of compulsory schooling and less than 1.5 years of vocational training or college), medium skilled (10 years of schooling and an apprenticeship) and high skilled (12 or 13 years of schooling and who have achieved a technical college degree, 3-4 years, or a university degree, 4-6 years). In order to generate complete work histories from first entry into work, we require that the low- and medium-skilled women are not older than 16 years of age in 1975 and the high-skilled women are not older than 23 years of age in 1975.

In our analyses, the main variables are the log of real daily wages ${ }^{17}$ for full-time work (more than 35 hours a week), work experience and the leave duration relating to first childbirth. The duration of leave is defined as the sum of the total length of work interruption relating to

\footnotetext{
${ }^{14}$ Formally, we want to use the longest period of protected leave throughout the observation window, that is 37.5 months. In our empirical implementation, we slightly extend this period to 42 months. How we define the cut-off point is important for the first stage of the estimator. In the second stage, the actual duration is used. We have modified the cut-off point to test robustness and results were not affected.

${ }^{15}$ This is to ensure the best quality of the parental leave variable. For more details on the construction of the variable see Appendix 7.2. See for a more general discussion in Schönberg (2009).

${ }^{16}$ We acknowledge that some of these women may have children later than 39 , or have had births before entry at a very young age.

${ }^{17}$ All wages are measured in Deutsche marks (DM). After 1998, Euros are converted into DM at the exchange rate of 1 Euro = 1.9553 DM. Wages are deflated by the Consumer Price Index, with 1995 as the base year.
} 
first birth (parental leave) and extended non-working periods immediately following. As we estimate the model in first differences, we use indicator variables for occupational change based on 3-digit occupation groups, sector change based on 12 sector groups, and plant changes. In addition, our instrumental variables for changes in parental leave duration are determined by the month and year of the reforms.

\subsection{Descriptive statistics}

The summary statistics of the mother and non-mother samples are presented in Table 2. We can see that age at first birth is 25 for low-skilled mothers and increases as education level increases. This corresponds to 5.6 years of work experience for the low-skilled mothers, and 4.8 years for high-skilled mothers at first birth. Entry wages differ considerably between the skill groups, showing the importance of entry conditions. Wage levels during the career also increase with education and experience. 16 - 19 per cent per year of workers change plant, and around 10 per cent per year change occupation.

[Table 2 about here]

The descriptives show two main findings. First, we find low return rates among mothers. On average, only 50 percent of mothers return to full-time employment, even within 3.5 years after birth. ${ }^{18}$ Second, the returning wage levels are some 5-10 per cent lower in real terms just after birth than in the last period before birth. Taken together this raises the question whether the wage drop is purely due to heterogeneity, or because the group of returning mothers is a selected group.

\footnotetext{
${ }^{18}$ Approximately one fourth return to part-time.
} 
The data also reflect typical findings that returns to experience, or wage growth, are relatively large early in careers and declining thereafter, as is mobility. Comparing mothers and non-mothers shows that entry wages for mothers are significantly smaller than for non-mothers, but the differences are not very substantial at only some 3-7 per cent. ${ }^{19}$

[Figure 1 about here]

Figure 1 depicts how the distribution of completed leave duration has changed throughout the reforms. The figure reveals spikes around the time of expiry of protected parental leave. The ratio of women not returning to full-time employment increased from 32 -37 per cent in 1981-85 to 50-56 per cent in 1992 and after. These patterns hold across the three education groups. Hence, despite the fact that the reforms made it more attractive to return to employment because a similar position was guaranteed, the actual return to work rate has declined (at least within the 3.5 years we regard as the medium run).

In the econometric analysis, we take into account general trends in the pattern of return to work and use the within-year variation induced by the reforms for identification. The variation we exploit can be illustrated by the reforms in January 1986 and in July 1989. The lower part of Table 3 reports that those women giving birth in the second half of 1989 (and commencing leave 6 weeks before expected birth) have a 2-6 percentage points lower probability of returning to work than those who give birth in the first half of 1989 . While the variation is smaller in the years when the reform takes place on 1 January, e.g. in 1986, we can still exploit this effect because the period of leave commences before birth.

[Table 3 about here]

\footnotetext{
${ }^{19}$ In the US, Lundberg and Rose (2000) found a difference of 9 per cent on average across all education groups.
} 


\section{Results}

\subsection{Estimation results}

We estimate the model in equation (1) by first differences estimation separately for the low-, medium- and high-skilled mothers and correct for the non-random decision to return to work after childbirth. In the first-stage probit regression in Table 4, we include in addition to the five dummy variables for the policy changes defined by month and year, exogenous variables from the wage equation in first differences, that is, changes in individual characteristics and the time dummies. All explanatory variables are measured at the last employment spell before birth. Our estimation results show very strongly that conditional on the controls, the reforms decrease the probability of returning to full-time employment for all education groups. Tests for joint significance of all the dummy variables for policy changes show that they are highly significant for all three education groups. Based on the probit estimation, we generate the control function (the inverse Mills ratio) and add it to our main wage regressions in first differences.

\section{[Table 4 and 5 about here]}

In Table 5 the estimation results from the control function approach are reported. ${ }^{20}$ The return to experience during early career and before birth is quite high. It is largest for lowskilled mothers, 8.9 per cent, for an increase from 3 to 4 years of experience and lowest for the high-skilled mothers, 4.0 per cent, respectively. An additional non-linear effect works through the time effects 3 years before birth that we allow for in the estimated wage model. This shows that even before childbirth, wages start to decline, except for the high skilled. Across all education groups, returns to experience substantially decrease after birth to around 2.6 (low-

\footnotetext{
${ }^{20}$ We have investigated robustness of our results which we describe in the Appendix 7.3.
} 
skilled mothers) and 2.1 (high-skilled mothers) per cent when experience increases from 3 to 4 years.

Extended parental leave in connection with birth leads to a significant wage decline in all education groups. For the medium-skilled, the fall is 5.8 per cent per year in real wages. It is somewhat lower for the high-skilled, just 4.4. per cent per year, but this is less precisely estimated. It is lowest for low-skilled mothers at only 3.4 per cent per year. The differences are only statistically significantly different between low- and medium-skilled mothers. The test for homogeneity across education groups is however rejected (See Table 5). It is interesting to note that while these are not negligible values, the estimated falls in real wages are smaller than those from simple first-difference estimates; for the estimation results, see Table $6 .{ }^{21}$ The fact that first differences yields smaller effects than previous studies may be because the effects are estimated separately by education group and more generally account for more heterogeneity than in other studies. Interestingly, the estimated effects decrease further once we control for non-randomness in the return process. Hence, the estimated effect by first differences is a composite effect. Simple calculations show that selection accounts for 40 per cent of the firstdifference estimate of the effect through leave duration for the low-skilled. The corresponding figures are 60 per cent for the medium-skilled and 53 per cent for the high-skilled. We regard the remaining effect as human capital depreciation. ${ }^{22}$

While other controls for mobility have economically plausible signs, interpretation is complicated as mobility may still be endogenous. The average effect of mobility during the entire

\footnotetext{
${ }^{21}$ These estimates are also smaller than findings from previous studies. See Beblo et al. (2009), Schoenberg et al. (2007). Both studies focus on full-time working women.

${ }^{22}$ As shown in a previous study using GSOEP data, we cannot rule out that part of this gap is explained by the loss of bonus payments and other fringe benefits. See Ejrnæs and Kunze (2004, pp. 43).
} 
period of observation is positive, particularly for plant mobility. However, in connection with the return after birth we find negative effects. For the low-skilled mothers the estimate is -7.5 per cent $(=5.3-12.8)$ and for medium-skilled mothers -2.2 per cent $(=5.4-7.6)$. It is not significant for the high-skilled.

[Figure 2 here]

In Table 5 we can see that the estimated coefficient for the control function is highly significant and negative for all three education groups. This reflects negative selection back to full-time employment among mothers. To illustrate the operation of negative selection, in Figure 2 we depict the predicted wage profile for a medium-skilled woman giving birth in 1990 who actually returns to full-time employment after 1 year of leave. We find that this woman compared to the "average" mother ${ }^{23}$ experiences a much larger drop in wages around the first birth. It implies that ignoring the selection process for a return to full-time employment will overestimate the mean drop in wages in connection with childbirth. A comparison between the education groups shows that negative selection is less pronounced for the low-skilled and more pronounced for the medium and high-skilled. ${ }^{24}$

In Figure 2 we also compare the same woman's wages to the hypothetical wages that she would experience without the birth, that is if she were to postpone first birth to very late, here $1999 .^{25}$ Then we see a gain from postponement, primarily, since the returns are highest during the early career, and returns decrease already before birth.

\footnotetext{
${ }^{23}$ The "average" mother is defined as a woman who has $\gamma_{i}$ equal to 0 , whereas the mother that returns has $\gamma_{i}$ equal to $E\left(\gamma_{i} \mid s_{i}^{t}=1\right)$.

${ }^{24}$ The figures for the low and high-skilled are available from the authors upon request.

${ }^{25}$ We chose as an example the postponement of first birth to 1999 since then until 1995 the profile is purely based on the estimated return to experience before birth.
} 
To illustrate the differences between the wage processes for mothers and non-mothers we also plot the predicted wage processes for a medium-skilled non-mother in Figure $2 .{ }^{26}$ As shown, non-mothers have a slightly higher entry wage but a lower return to experience at the beginning of their labour market career. However, the average returns to experience after birth (for those women having children) is much lower than before birth, and is also low when compared to non-mothers. The comparison reveals three sources of family gap for those who have children: the wage level of mothers is comparably low at first entry (see Table 2) and decreases just before birth, they fall behind because of a wage decline on return after leave, and their return to experience is relatively low after birth.

\subsection{Discussion}

While the negative selection of return to work may be surprising, particularly for all education groups, it is consistent with a number of economic explanations. Our data, however, are too limited to pinpoint which of these best fits the data. Negative selection can, for example, arise because of assortative matching. If highly productive women are married to highly productive men with high earnings, these women can work less and therefore the negative selection is driven by an income effect. The negative selection could also be generated through specialization in work after birth and by purchasing childcare. This outcome can be derived in a model extending Becker 's (1985) one-period model to a two-period model (before and after first birth) where the effort intensity of household production increases after birth. In this case, wages will decline after birth because more effort is devoted to housework. The finding may also capture that highly productive women choose to space their births closer and therefore do not return to work

\footnotetext{
${ }^{26}$ The complete results for the non-mother samples are reported in Appendix 7.4.
} 
within 3.5 years. $^{27}$ Other explanations could follow from a backward-bending labour supply curve.

The negative selection is also interesting from a policy perspective. As we have seen, negative selection implies a tendency to overestimate the mean loss from childbirth if this aspect is ignored. This is important if employers form their expectations about the productivity losses of mothers on the basis of what they observe (which means the performance of women who actually returned). Employers will then overestimate the losses and this means that if an "average mother" decides to return, she would actually be paid too low a wage because of statistical discrimination.

[Figure 3 here]

To illustrate this aspect, we compare the impact of the reforms during the late 1980s. In Figure 3, we plot the predicted wage paths for a medium-skilled woman giving birth in 1981 and hypothetically the same woman giving birth in 1990. The wage profile of the "average mother" is not affected by the reforms, but if we only look at those who actually return, the drop in wages becomes much larger for the woman giving birth in 1990 compared to the same woman giving birth in 1981. The expansion of parental leave has the effect that the fraction of mothers returning to full- time employment declines, and this leads to an indirect effect on those mothers who actually do return because they are more exposed to statistical discrimination. These indirect effects of parental leave schemes on labour supply are important for the design of parental leave schemes, as this mechanism induces relatively less productive mothers to return.

Our results focus on the wage processes of women staying highly attached in the labour

\footnotetext{
${ }^{27}$ Kreyenfeld (2002) showed for West Germany that approximately 50 per cent of all mothers, born between 1961 and 1963, have a second birth within 3.5 years.
} 
market, that is, those who return to a full-time career after birth, which amounts to an important and large group of women. In order to generalize results a concern is that the definition of highly attached may be restrictive, primarily, since it does not include those who temporarily switch to part-time work and then return to full-time work. While the IABS data are too limited to make wages from full-time work and part-time work comparable, we argue that inclusion of wages from part-time work would not change our main results on negative selection. It might be that the most productive women temporarily transit into part-time work. However, even if this were the case our results will still show that there exists a potential for an increase of the labour force with on average more productive women; in this case by encouraging mothers in part-time work to return to full-time employment. The size of the potential increase in the labour force will of course depend on how many and how fast these women in part-time work return to full-time.

\section{Concluding remarks}

In this study, we analysed women's wage processes for Germany with a particular focus on the phase around first birth. We found that the selection process of return to work and the wage process around birth are strongly related. The results also indicate negative selection, i.e. mothers who suffer from relatively large wage losses in connection with birth are those relatively more likely to return to full-time employment after birth. Women's wages are negatively affected by the duration of leave relating to birth. Furthermore, the return to experience is lower after childbirth than before, and lower for mothers than for non-mothers. Comparisons across education groups reveal considerable heterogeneity. Finally, we document that the wage processes of women who become mothers and women who remain childless develop very 
differently, despite small differences at labour market entry.

Our results contrast with previous findings for Germany that have shown large declines in wages after birth by international standards for women in full-time work (Schoenberg et al., 2007; Beblo et al. 2008). Our findings suggest that estimates conditional on returning to work underestimate the average productivity of women with small children. Furthermore, our results demonstrate that the expansionary parental leave policy actually did not create incentives for highly productive mothers to return to work. These findings have important implications. First, expansionary reforms between 1985 and 1995 have prevented the improvement of mothers' positions in the labour market. Some indicators of this are the decline in the return rate to full-time work across this period and the increase in the average duration of leave. Second, given mothers who return to work relatively shortly after birth are a negatively selected group, firms may have excessively low expectations about the mean productivity of all mothers.

A question following from our analysis is whether non-random selection back to work is generally of importance for studies on the wage changes of women around birth and the family gap. One argument that this is potentially a more general issue, is that the employment rates of women with young children are lower than for women overall in many countries. The result of negative selection may arguably be important for countries with parental leave and childcare institutions similar to Germany. In addition, the career changes of women after birth are widely observed and a question is what fraction of women return to their pre-birth (highly attached) profile. Only detailed analyses of large longitudinal micro data can reveal such compositional changes. We consider these questions of broad interest for future research. 


\section{References}

[1] Anderson, D., M. Binder and K. Krause (2002): The Motherhood Wage Penalty: Which Mothers Pay it and Why?, American Economic Review, 92(2), pp. 354-358.

[2] Beblo, M., S. Bender and E. Wolf (2009): Establishment-level Wage Effects of Entering Motherhood, Oxford Economic Papers, 61, pp. i11-i34.

[3] Becker, G. (1985): Human Capital, Effort, and the Sexual Division of Labor, Journal of Labor Economics, 3(1), pt. 2, pp. S34-S58.

[4] Bender, S., A. Haas and C. Klose (2000). The IAB Employment Subsample 1975-1995. Schmollers Jahrbuch Zeitschrift für Wirtschafts- und Sozialwissenschaften/Journal of Applied Social Science Studies, 120(4), pp. 649-662.

[5] Blundell, R. and M.C. Dias (2009): Alternative Approaches to Evaluation in Empirical Microeconomics, Journal of Human Resources, 44(1), pp. 565-640.

[6] Burgess, S., P. Gregg, C. Propper and E. Washbrook (2008): Maternity Rights and Mothers' Return to Work, Labour Economics, 15, pp. 168-201.

[7] Datta Gupta, N. and N. Smith, (2002): Children and Career interruptions: The Family Gap in Denmark, Economica, 69, pp. 609-629.

[8] Davies, R. and G. Pierre (2005): The Family Gap in Pay in Europe: A Cross-Country Study, Labour Economics, 12(4), pp. 469-486.

[9] Dustmann, C. and Schönberg, U. (2008): The Effect of Expansions in Maternity Leave Coverage on Children's Long-Term Outcomes. IZA Discussion Paper No. 3605. 
[10] Ejrnæs, M. and A. Kunze (2004): Wage Dips and Drops around First Birth, IZA Discussion Paper No. 1011.

[11] Harkness, S. and J. Waldfogel (2003): The Family Gap in Pay: Evidence from Seven Industrialized Countries, Journal of Labor Research, 22, pp. 369-415.

[12] Kreyenfeld, M. (2002): Time-squeeze, partner effect or selfselection? An investigation into the positive effect of women's education on second birth risks in West Germany, Demographic Research, 7(2), pp. 15-48.

[13] Kunze, A. (2002): The Timing of Working Career and Depreciation of Human Capital, Discussion Paper No. 509, IZA, Bonn.

[14] Lalive, R. and J. Zweimüeller (2009): How Does Parental Leave Affect Fertility and Return to Work? Evidence from Two Natural Experiments, Quarterly Journal of Economics, 124(3), pp.1363.

[15] Lundberg, S. and E. Rose (2000): Parenthood and the Earnings of Married Men and Women, Labour Economics, 7(6), pp. 689-710.

[16] Nielsen, H. Skyt, M. Simonsen and M. Verner (2004): Does the Gap in Family-Friendly Policy Drive the Family Gap?, Scandinavian Journal of Economics, 106(4), pp. 721-744.

[17] OECD (2001): Employment Outlook, Paris.

[18] Ondrich, J., C.K. Spiess and Q. Yang (1996): Barefoot and in a German Kitchen: Federal Parental Leave and Benefit Policy and the Return to Work after Childbirth in Germany, Journal of Population Economics, 9(3), pp. 247-266. 
[19] Ondrich, J. et al. (2003): The Liberalization of Maternity Leave Policy and the Return to Work after Childbirth in Germany, Review of Economics of the Household, 1, pp. 77-110.

[20] Ruhm C. (1998): The Economic Consequences of Parental Leave Mandates: Lessons From Europe, Quarterly Journal of Economics, 113(1), pp. 285-317.

[21] Schönberg, U. and J. Ludsteck (2007): Maternity Leave Legislation, Female Labor Supply, and the Family Wage Gap, DP IZA.

[22] Schönberg, U. (2009): Does the IAB Employment Sample Reliably Identify Maternity Leave Taking? A Data Report, Zeitschrift für Arbeitsmarktforschung - Journal of Labour Market Research, 42, pp. 49-70.

[23] Waldfogel, J. (1998a): The Family Gap for Young Women in the United States and Britain: Can Maternity Leave Make a Difference?, Journal of Labor Economics, 16(3), pp. 505-545.

[24] Waldfogel, J. (1998b): Understanding the "Family Gap" in Pay for Women with Children, Journal of Economic Perspectives, 12(1), pp. 137-156.

[25] Zmarzlik, J., M. Zipperer, H.P. Viethen and G. Viess (1999): Mutterschaftsgesetz, Mutterschutzleistungen, Bundeserziehungsgeldgesetz, Carl Heymanns Verlag KG, Koeln, 8th edition. 
Table 1: Parental leave durations between 1979 and 2001

\begin{tabular}{|c|c|c|c|c|}
\hline \multirow[b]{2}{*}{$\begin{array}{l}\text { Children } \\
\text { born between.. }\end{array}$} & \multicolumn{4}{|c|}{ Job-protected leave } \\
\hline & $\begin{array}{l}\text { Maternity } \\
\text { leave }^{1} \\
\text { paid }\end{array}$ & $\begin{array}{l}\text { Parental } \\
\text { leave [benefit eligibility] } \\
\text { month } 3 \text { plus after birth }\end{array}$ & $\begin{array}{l}\text { Total protected leave } \\
\text { before and after } \\
\text { birth }\end{array}$ & $\begin{array}{l}\text { Hours } \\
\text { of } \\
\text { part-time } \\
\text { per week }{ }^{2}\end{array}$ \\
\hline 1.7.1979-31.12.1985 & $1.5+2$ months & 4 months [4 months] & 7.5 months & \\
\hline $1.1 .1986-31.12 .1987$ & $1.5+2$ months & 8 months $[8$ months] & 11.5 months & 15 \\
\hline 1.1.1988-30.6.1989 & $1.5+2$ months & 10 months [10 months] & 13.5 months & 15 \\
\hline 1.7.1989-30.6.1990 & $1.5+2$ months & 13 months [13 months] & 16.5 months & 19 \\
\hline 1.7.1990-31.12.1991 & $1.5+2$ months & 16 months [16 months] & 19.5 months & 19 \\
\hline $1.1 .1992-31.12 .1992$ & $1.5+2$ months & 34 months [16 months] & 37.5 months & 19 \\
\hline $1.1 .1993-30.12 .2000$ & $1.5+2$ months & 34 months [22 months] & 37.5 months & 19 \\
\hline
\end{tabular}

Notes: ${ }^{1}$ Maternity leave is fully paid based on average wage during the three months before birth.

2 These are the number of hours one is allowed to work while on leave.

Sources: Mutterschutzgesetz 25.06.1979,

Bundeserziehungsgeldgesetz 6.12.1986 and newer versions. Zmarzlik, et al. (1999). 


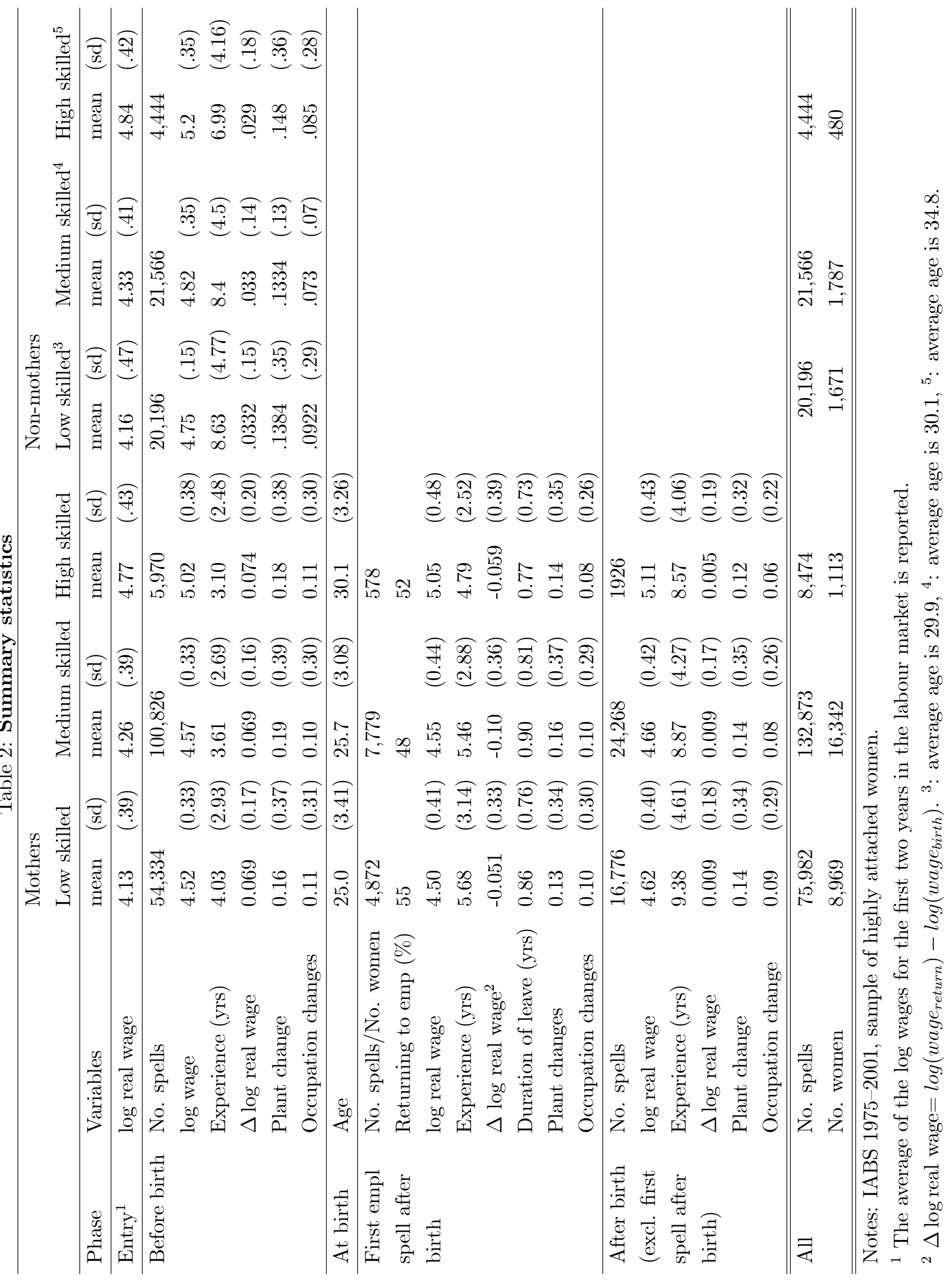


Table 3: The return rate of mothers going on parental leave in 1985 and 1989

\begin{tabular}{|c|c|c|c|c|c|c|c|c|}
\hline \multirow[t]{2}{*}{ Leave starts } & \multirow{2}{*}{$\begin{array}{l}\text { Appr. date of } \\
\text { first birth }\end{array}$} & \multirow{2}{*}{$\begin{array}{l}\text { Max. leave } \\
\text { (months) }\end{array}$} & \multicolumn{2}{|c|}{ Low skilled } & \multicolumn{2}{|c|}{ Medium skilled } & \multicolumn{2}{|c|}{ High skilled } \\
\hline & & & no obs & pct & no obs & pct & no obs & pct \\
\hline $1.1-31.10 .1985$ & $1.3-31.121985$ & 7.5 & 564 & 64.18 & 920 & 64.35 & 53 & 67.92 \\
\hline $1.11-31.12 .1985$ & $1.1-28.21986$ & 11.5 & 39 & 58.97 & 53 & 49.06 & 3 & 66.67 \\
\hline \multicolumn{3}{|c|}{ Test for no difference $\chi_{(1)}^{2}(p-$ value $)$} & \multicolumn{2}{|c|}{$0.42(p=0.51)$} & \multicolumn{2}{|c|}{$5.05(p=0.03)$} & \multicolumn{2}{|c|}{$0.01(p=0.96)$} \\
\hline 1.1-30.4.1989 & $1.1-30.61989$ & 13.5 & 283 & 49.47 & 538 & 48.33 & 39 & 56.41 \\
\hline 1.5-31.12.1989 & 1.7-31.12 1989 & 16.5 & 419 & 47.73 & 732 & 43.31 & 38 & 50.00 \\
\hline \multicolumn{3}{|c|}{ Test for no difference $\chi_{(1)}^{2}(p-$ value $)$} & \multicolumn{2}{|c|}{$0.20(p=0.65)$} & \multicolumn{2}{|c|}{$3.15(p=0.08)$} & \multicolumn{2}{|c|}{$0.31(p=0.58)$} \\
\hline
\end{tabular}

Notes: IABS 1975-2001, sample of highly attached mothers.

Table 4: Selection equation: return or not return to fulltime work after birth decision estimated as a probit model

\begin{tabular}{lllllll} 
& \multicolumn{2}{c}{ Low skilled } & \multicolumn{2}{c}{ Medium skilled } & \multicolumn{2}{l}{ High skilled } \\
& coef. & s.e. & coef. & s.e. & coef. & s.e. \\
\hline$\Delta$ Experience $(\mathrm{yrs})$ & .074 & $(.072)$ & -.057 & $(.052)$ & -.133 & $(.214)$ \\
$\Delta$ Experience $(\mathrm{yrs})^{2}$ & $-.013^{* * *}$ & $(.002)$ & $-.006^{* * *}$ & $(.002)$ & -0.009 & $(.008)$ \\
Plant change & .041 & $(.068)$ & $.107^{* *}$ & $(.046)$ & $.643^{* * *}$ & $(.200)$ \\
Occupation change & .036 & $(.073)$ & $.156^{* * *}$ & $(.056)$ & .190 & $(.248)$ \\
\hline Protected leave in months (period) & & & & & \\
Leave=10 $(1 / 1986-12 / 1987)$ & -.125 & $(.121)$ & -.135 & $(.090)$ & $-.809^{*}$ & $(.437)$ \\
Leave=12 $(1 / 1988-6 / 1989)$ & $-.220^{*}$ & $(.123)$ & $-.329^{* * *}$ & $(.090)$ & $-.867^{* *}$ & $(.417)$ \\
Leave=15 $(7 / 1989-6 / 1990)$ & $-.420^{* * *}$ & $(.128)$ & $-.607^{* * *}$ & $(.092)$ & $-.995^{* *}$ & $(.418)$ \\
Leave=18 $(7 / 1990-12 / 1991)$ & $-.523^{* * *}$ & $(.128)$ & $-.705^{* * *}$ & $(.091)$ & $-1.284^{* * *}$ & $(.394)$ \\
Leave=36 $(1 / 1992-12 / 1995)$ & $-.759^{* * *}$ & $(.138)$ & $-.654^{* * *}$ & $(.091)$ & $-1.034^{* * *}$ & $(.367)$ \\
\hline Number of observations & 8,969 & & 16,342 & & 1,113 & \\
Pseudo R-squared & 0.028 & & 0.022 & & 0.044 &
\end{tabular}

Test for joint significance of the leave duration variables

Test statistic $\chi_{(5)}^{2} \quad 36.95 \quad(\mathrm{p}=0.00) \quad 92.49 \quad(\mathrm{p}=0.00) \quad 11.74 \quad(\mathrm{p}=0.04)$

Notes: IABS 1975-2001, sample of highly attached mothers.

Other controls are included for year and industry. 
Table 5: Estimation results of the wage regression in first differences (control function approach) for mother sample

Low skilled Medium skilled High skilled

coef. (s.e.) coef. (s.e.) coef. (s.e.)

Variables before first birth

\begin{tabular}{lllllll}
\hline$\Delta$ Experience (yrs) & $.138^{* * *}$ & $(.003)$ & $.109^{* * *}$ & $(.002)$ & $.065^{* * *}$ & $(.008)$ \\
$\Delta$ Experience (yrs) & $-.007^{* * *}$ & $(.001)$ & $-.006^{* * *}$ & $(.000)$ & $-.004^{* * *}$ & $(.001)$ \\
Dummy for 3 years before & $-.013^{* * *}$ & $(.001)$ & $-.010^{* * *}$ & $(.001)$ & .007 & $(.005)$ \\
\hline \multicolumn{7}{l}{ Variables in connection with first birth } \\
\hline Duration of leave (yrs) & $-.034^{* * *}$ & $(.007)$ & $-.058^{* * *}$ & $(.006)$ & $-.044^{*}$ & $(.023)$ \\
Plant change* (mat. leave) & $-.128^{* * *}$ & $(.018)$ & $-.076^{* * *}$ & $(.012)$ & .049 & $(.051)$ \\
Occupation change*(mat.leave) & .021 & $(.030)$ & -.005 & $(.016)$ & -0.08 & $(.069)$ \\
\hline & Variables after first birth & & & \\
\hline$\Delta$ Experience (yrs) & $.024^{* * *}$ & $(.003)$ & $.026^{* * *}$ & $(.004)$ & $.026^{* *}$ & $(.025)$ \\
$\Delta$ Experience (yrs) & $.0004^{* *}$ & $(.0001)$ & -.000 & $(.0002)$ & -.001 & $(.001)$ \\
\hline & Other controls & & & & \\
\hline Plant change & $.053^{* * *}$ & $(.003)$ & $.054^{* * *}$ & $(.001)$ & $.031^{* * *}$ & $(.001)$ \\
Occupation change & $.008^{* *}$ & $(.004)$ & $.012^{* * *}$ & $(.002)$ & $.040^{* * *}$ & $(.012)$ \\
Inverse Mills ratio & $-.046^{* * *}$ & $(.010)$ & $-.082^{* * *}$ & $(.008)$ & $-.084^{* *}$ & $(.034)$ \\
\hline Number of observations & 75,982 & & 132,873 & & 8,474 & \\
Number of individuals & 8,969 & & 16,342 & & 1,113 & \\
R-squared & 0.154 & & 0.166 & & 0.110 & \\
\hline
\end{tabular}

Test for educational homogeneity

Test statistic $\chi^{2}(92) \quad 343.66 \quad$ p-value 0.00

Notes: IABS 1975-2001, sample of highly attached mothers.

Other controls are included for year and industry. 
Table 6: Estimation results of the wage regression in first differences for mother sample

\begin{tabular}{|c|c|c|c|c|c|c|}
\hline & \multicolumn{2}{|c|}{ Low skilled } & \multicolumn{2}{|c|}{ Medium skilled } & \multicolumn{2}{|c|}{ High skilled } \\
\hline & coef. & (s.e.) & coef. & (s.e.) & coef. & (s.e.) \\
\hline & \multicolumn{6}{|c|}{ Variables before first birth } \\
\hline$\Delta$ Experience $(\mathrm{yrs})$ & $.137^{* * *}$ & $(.003)$ & $.108^{* * *}$ & $(.002)$ & $.064^{* * *}$ & $(.008)$ \\
\hline$\Delta$ Experience $(\mathrm{yrs})^{2}$ & $-.007^{* * *}$ & $(.001)$ & $-.006^{* * *}$ & $(.000)$ & $-.004^{* * *}$ & $(.001)$ \\
\hline \multirow[t]{2}{*}{ Dummy for 3 years before } & $-.013^{* * *}$ & $(.001)$ & $-.010^{* * *}$ & $(.001)$ & .007 & $(.005)$ \\
\hline & \multicolumn{6}{|c|}{ Variables in connection with first birth } \\
\hline Duration of leave (yrs) & $-.055^{* * *}$ & $(.005)$ & $-.096^{* * *}$ & $(.004)$ & $-.083^{* * *}$ & $(.018)$ \\
\hline Plant change* (mat. leave) & $-.130^{* * *}$ & $(.019)$ & $-.086^{* * *}$ & $(.012)$ & .040 & $(.051)$ \\
\hline Occ. change*(mat.leave) & .021 & $(.020)$ & -.005 & $(.016)$ & -.096 & $(.068)$ \\
\hline & \multicolumn{6}{|c|}{ Variables after first birth } \\
\hline$\Delta$ Experience $(\mathrm{yrs})$ & $.019^{* * *}$ & $(.003)$ & $.014^{* * *}$ & $(.004)$ & .022 & $(.025)$ \\
\hline \multirow[t]{2}{*}{$\Delta$ Experience $(\mathrm{yrs})^{2}$} & $.0004^{* *}$ & $(.0001)$ & -.000 & $(.000)$ & -.001 & $(.001)$ \\
\hline & \multicolumn{6}{|c|}{ Other controls } \\
\hline Plant change & $.053^{* * *}$ & $(.003)$ & $.054^{* * *}$ & $(.002)$ & $.032^{* * *}$ & $(.010)$ \\
\hline Occupation change & $.008^{* *}$ & $(.004)$ & $.012^{* * *}$ & $(.002)$ & $.039^{* * *}$ & $(.012)$ \\
\hline Number of observations & 75,982 & & 132,873 & & 8,474 & \\
\hline Number of individuals & 8,969 & & 16,342 & & 1,113 & \\
\hline R-squared & 0.153 & & 0.164 & & 0.108 & \\
\hline
\end{tabular}

Test for educational homogeneity

Test statistic $\chi^{2}(90) \quad 336.50 \quad$ p-value $\quad 0.00$

Notes: IABS 1975-2001, sample of highly attached mothers.

Other controls are included for year and industry. 
Figure 1: The distribution of actual leave by education groups

Low skilled

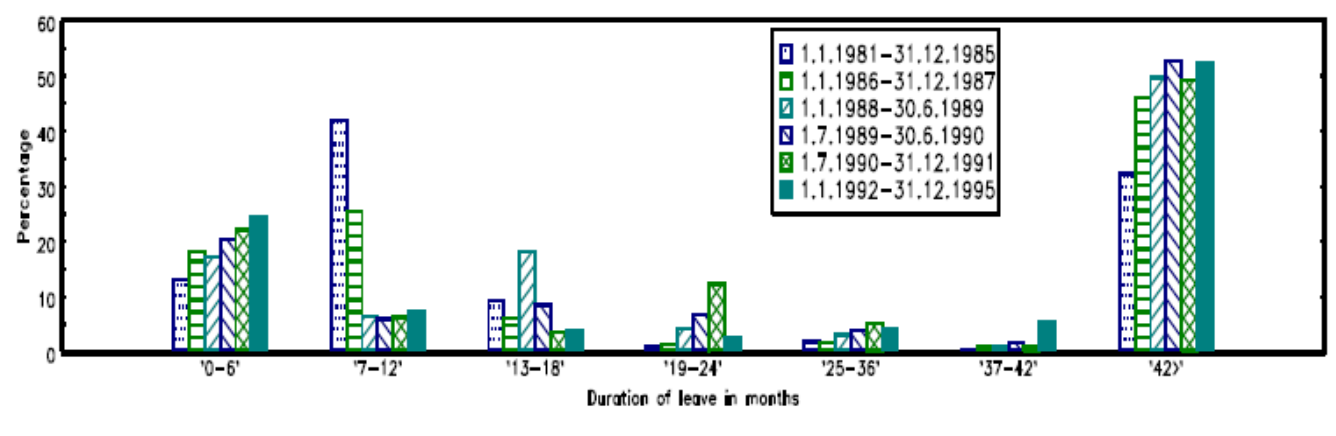

Medium skilled

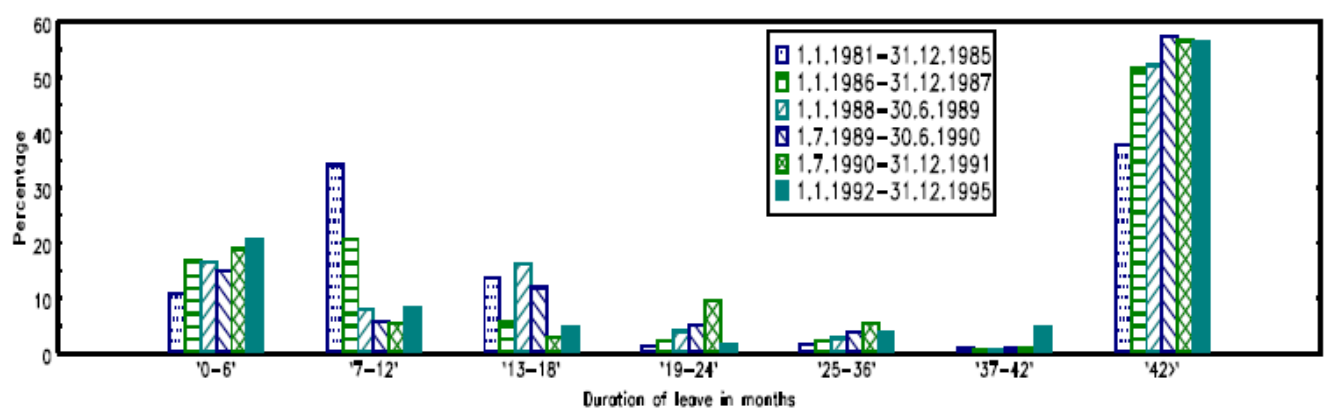

High skilled

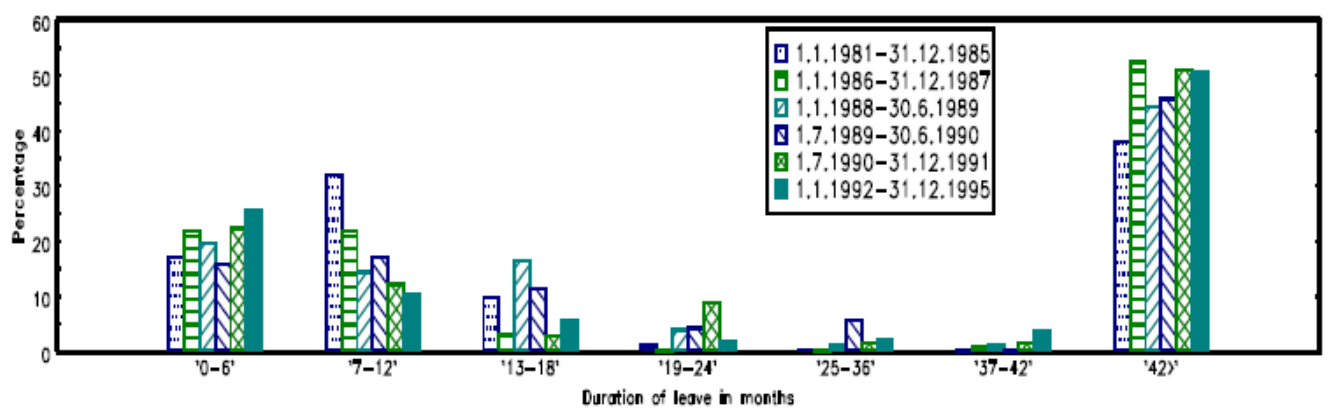

Notes: IABS 1975-2001, sample of highly attached mothers. 
Figure 2: The predicted wage profiles for medium-skilled women

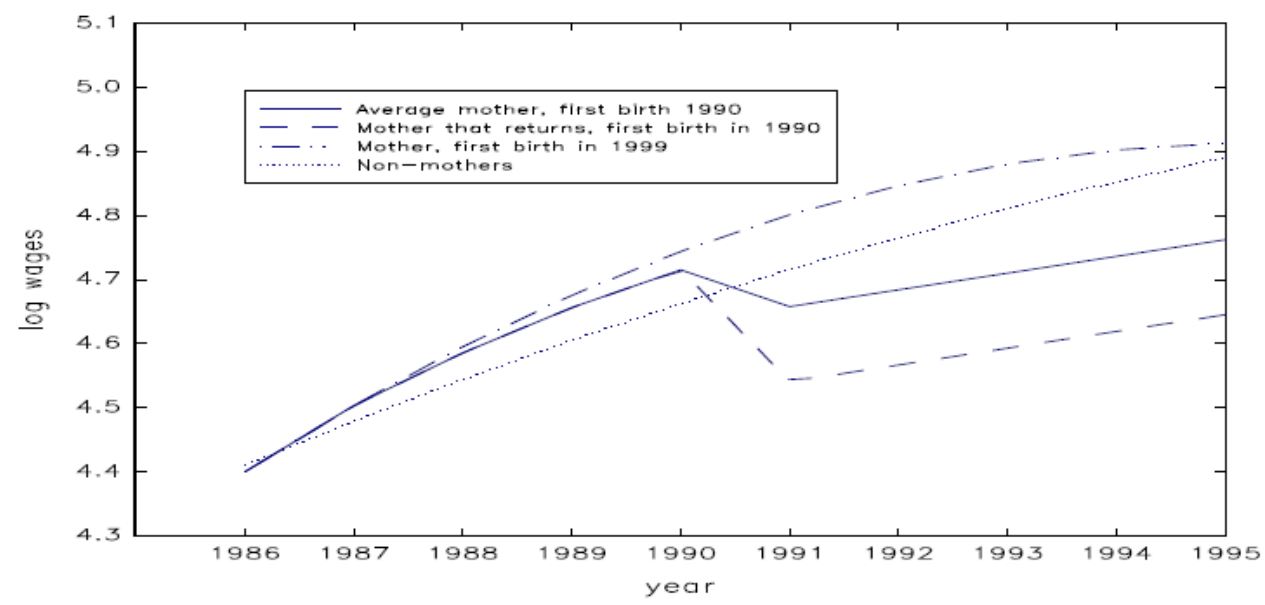

Notes: The predicted wage profiles assume entry into first job in 1986 and that non-mothers work throughout the entire period. Women in the mother group experience first birth, depicted in 1990, followed by one year of parental leave. It is assumed that all stay in the same occupation and plant since entry. Effects from calendar years are neglected. Calculations are based on our estimates.

Figure 3: The predicted wage profiles for medium-skilled mothers giving birth in 1981 and 1990

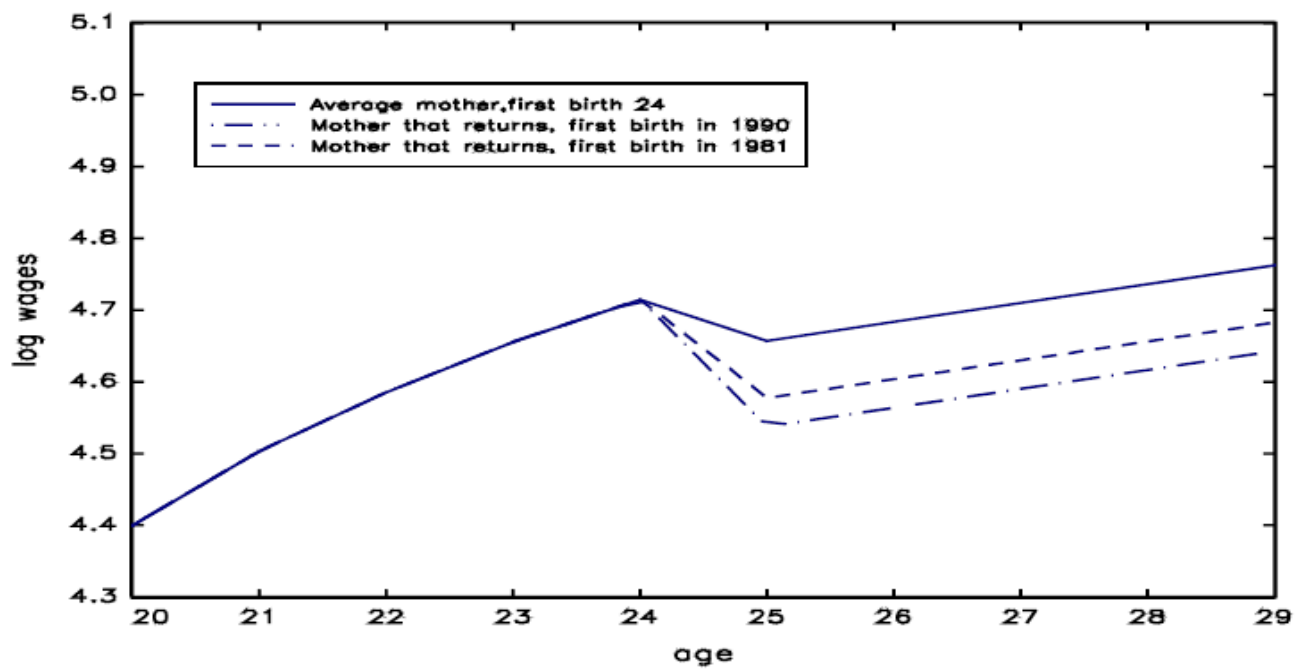

Notes: The predicted wage profiles assume entry into first job at age 20 , birth at age 24 and return to full-time employment after one year of leave from work. It is assumed that all stay in the same occupation and plant since entry. Effects from calendar years are neglected. Calculations are based on our estimates. 


\section{Appendix}

\subsection{Data}

The IABS is representative for the population of workers in Germany who are covered by social security. It is a 2 per cent random sample of workers in every period and for all of the workers complete time series during the observation window 1975-2001 are included. The sample is drawn from the (100 per cent) employment statistics, collected by the German Federal Bureau of Labour. Data from the employment statistics are supplemented by information on benefit receipt (Leistungsempfaengerdatei) and information about the plant.

Wages in the data are reported as daily wages (income during a spell divided by the number of days of employment). Contributions to social security have to be paid only up to a limit. This implies that wages are topcoded in the IABS but as we have calculated top coding affects only 4 per cent of wages in our sample of young women. We drop jobs with wages that fall below the lower bound of social security eligibility. We define full-time daily wages as wages in jobs with more than 35 hours per week.

The data includes information on every change in working status distinguished into work, interruptions and unemployment and these changes are reported on a calendar date basis. Mobility (establishment, occupation and sector) induces a new spell in the IABS and, hence, wage changes can be measured accurately. If the employee changes establishment or the position within the establishment, the employment spell ends and a new spell starts. Moreover, the establishment has to report all information by 1 January every year that leads to individual records with at least one spell per year, if employed, and no employment spell exceeding 1 year. Unemployment is reported in case of receipt of unemployment insurance or unemployment assistance. Interruptions indicate that the employer-employee relationship is on hold, yet the contract is still valid. In this case no wage payments are made. Every other status that does not fall into either of these categories results in a gap of the individual record of spells reported in the data.

\subsection{Construction of duration of leave related to first birth}

A core variable to our analysis is the duration of leave in connection with first child birth. This variable we measure by the duration of the first interruption since entry into the labour market and only for women who have worked full time until start of maternity leave (highly attached women). By law for every employed woman the firm has to grant maternity leave 6 weeks before expected birth and at least 2 months after. Hence, technically, every birth leads to a report of an interruption in the IABS as long as the woman is employed. Interruptions may also be reported if a worker is absent for a longer period because of health problems, for example. While we cannot exclude this by the available data that lacks accurate information on number of children and health, this has been shown in Schoenberg (2009) to be only a problem in less than 9 
Table 1: Number of leave durations in the sample of mothers from the IABS

\begin{tabular}{llll} 
& low skilled & medium skilled & high skilled \\
\hline 1981 & 350 & 286 & 24 \\
1982 & 425 & 395 & 28 \\
1983 & 519 & 514 & 41 \\
1984 & 524 & 723 & 35 \\
1985 & 603 & 973 & 56 \\
1986 & 577 & 827 & 37 \\
1987 & 565 & 1,024 & 63 \\
1988 & 644 & 1,130 & 56 \\
1989 & 702 & 1,270 & 75 \\
1990 & 762 & 1,394 & 83 \\
1991 & 728 & 1,470 & 96 \\
1992 & 664 & 1,415 & 100 \\
1993 & 641 & 1,513 & 119 \\
1994 & 655 & 1,696 & 143 \\
1995 & 610 & 1,712 & 157 \\
\hline In total & 8,969 & 16,342 & 1,113 \\
\hline
\end{tabular}

per cent of all interruptions (including interruptions at older ages) for women of childbearing ages. We argue that this, like health reason induced interruptions, is a rare event for highly attached young women and first interruptions as in our sample. ${ }^{1}$ Since leaves for consecutive births can be taken straight after one another and we do not observe the number of births, we acknowledge that some leaves are taken in connection with more than one birth. This effect is increasing the tighter the spacing between births and perhaps increasingly relevant for highly skilled mothers who start later in life to form families. Another issue is that leave starts 6 weeks before expected birth. But eligibility rules are determined by actual birth dates that we do not observe. We use the rule that the date of start of leave plus 4 weeks determines which regime applies. Since virtually all births are 2 weeks before or after expected date of birth we capture almost all births by this rule but we acknowledge that to some we connect too long duration eligibility. This may lead to underestimation of the effect on return. In Table (1) we show numbers of leave durations related to first birth by year and by skill group in our sample of highly attached women.

\footnotetext{
${ }^{1}$ Schoenberg (2009) uses data on fertility from not-publicly available pension data that were merged for a method report to the IABS at IAB. Applying less restrictive rules than those in this study less than 9 percent are not leaves due to births. Note, the sample includes higher order births.
} 


\subsection{Robustness of the results}

To investigate how robust our results are to changes in the model specification we have performed various sensitivity checks. First, regarding the selection equation, we have modelled the duration of the leave by a double censored Tobit model and constructed the control function on the basis of this model. The magnitude of the coefficients are unchanged but less precisely estimated and the negative selection is still found. Second, we have also examined the assumption regarding the post-birth effects, that is the case that $E\left(\gamma_{i}\right) \neq 0$, which implies that if $E\left(\gamma_{i}\right)<0$ on average all mothers are less productive after birth. This leads to a decrease of the effects of duration of leave, but the negative selection results survive. Third, in the main equation we have tried a more flexible form of the duration of leave variable. Using a non-linear term in the duration of leave did not change the results. We have tried using dummy variables and a polynomial instead of including the duration as a linear function. Furthermore, we have also tried to include a dummy for childbirth and the duration of the interruption. We have also experimented changing the cut-of point for the return decision from three and a half to one or two years. In both cases the effect through negative selection becomes slightly smaller but remains significant.

\subsection{Estimation results for non-mothers}

Table 2: Estimation results of the wage regression model in first differences for the non mother sample

\begin{tabular}{llll} 
Variable & low skilled & medium skilled & highly skilled \\
\hline & coef. (s.e.) & coef. (s.e.) & coef. (s.e.) \\
\hline$\Delta$ Experience & $.044(.005)^{* * *}$ & $.048(.006)^{* * *}$ & $.049(.016)^{* * *}$ \\
$\Delta$ Experience $^{2}$ & $-.001(.0001)^{* * *}$ & $-.001(.0001)^{* * *}$ & $-.001(.0003)^{* * *}$ \\
Occupation change & $.004(.007)$ & $-.003(.007)$ & $-.001(.019)$ \\
Firm change & $.036(.005)^{* * *}$ & $.041(.004)^{* * *}$ & $.03(.014)^{* * *}$ \\
\hline Number of observations & 20,196 & 21,566 & 4,444 \\
Number of individuals & 1,671 & 1,787 & 480 \\
R-squared & .1028 & .095 & .0613 \\
\hline
\end{tabular}

Notes: IABS 1975-2001, sample of highly attached women.

Other controls are included for year and industry. 